\title{
New Pulsed Power Technology for High Current Accelerators
}

G. J. Caporaso

This article was submitted to 2002 International Power modulator Conference, Hollywood, CA., June 30-July 3, 2002

\section{June 27, 2002}

U.S. Department of Energy

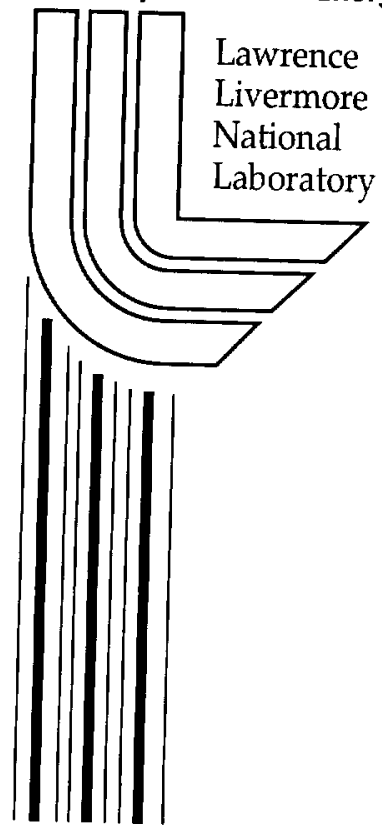




\section{DISCLAIMER}

This document was prepared as an account of work sponsored by an agency of the United States Government. Neither the United States Government nor the University of California nor any of their employees, makes any warranty, express or implied, or assumes any legal liability or responsibility for the accuracy, completeness, or usefulness of any information, apparatus, product, or process disclosed, or represents that its use would not infringe privately owned rights. Reference herein to any specific commercial product, process, or service by trade name, trademark, manufacturer, or otherwise, does not necessarily constitute or imply its endorsement, recommendation, or favoring by the United States Government or the University of California. The views and opinions of authors expressed herein do not necessarily state or reflect those of the United States Government or the University of California, and shall not be used for advertising or product endorsement purposes.

This is a preprint of a paper intended for publication in a journal or proceedings. Since changes may be made before publication, this preprint is made available with the understanding that it will not be cited or reproduced without the permission of the author.

This work was performed under the auspices of the United States Department of Energy by the University of California, Lawrence Livermore National Laboratory under contract No. W-7405-Eng-48.

This report has been reproduced directly from the best available copy.

Available electronically at http://www.doc.gov/bridge

Available for a processing fee to U.S. Department of Energy

And its contractors in paper from

U.S. Department of Energy

Office of Scientific and Technical Information

P.O. Box 62

Oak Ridge, TN 37831-0062

Telephone: (865) 576-8401

Facsimile: (865) 576-5728

E-mail: reports@adonis.osti.gov

Available for the sale to the public from

U.S. Department of Commerce

National Technical Information Service

5285 Port Royal Road

Springfield, VA 22161

Telephone: (800) 553-6847

Facsimile: (703) 605-6900

E-mail: orders@ntis.fedworld.gov

Online ordering: http://www.ntis.gov/ordering.htm

\section{OR}

Lawrence Livermore National Laboratory Technical Information Department's Digital Library http://www.llnl.gov/tid/Library.html 


\title{
New Pulsed Power Technology for High Current Accelerators *
}

\author{
G. J. Caporaso \\ Lawrence Livermore National Laboratory
}

\begin{abstract}
Recent advances in solid-state modulators now permit the design of a new class of high current accelerators. These new accelerators will be able to operate in burst mode at frequencies of several $\mathrm{MHz}$ with unprecedented flexibility and precision in pulse format. These new modulators can drive accelerators to high average powers that far exceed those of any other technology and can be used to enable precision beam manipulations. New insulator technology combined with novel pulse forming lines and switching may enable the construction of a new type of high gradient, high current accelerator. Recent developments in these areas will be reviewed.
\end{abstract}

\section{ADVANCED X-RAY RADIOGRAPHY AS A DRIVER FOR NEW TECHNOLOGY}

Much of the technology reported on in this paper was stimulated by an early concept for an advanced $x$-ray radiography facility using induction linacs [1].

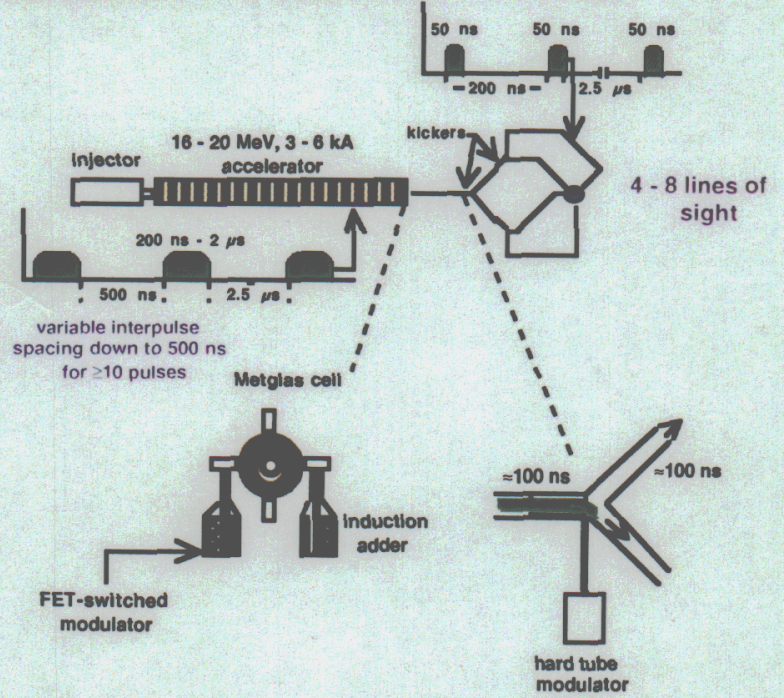

Figure 1. Advanced $\mathrm{x}$-ray radiography concept. A single accelerator with solid-state modulators is able to produce a high repetition rate, variable width pulse train which is split temporally by a fast kicker system. The kicker is able to feed a distribution network so that beam segments approach the test object from different lines of sight repeatedly as the experiment progresses.

Existing flash $\mathrm{x}$-ray machines deliver a single pulse per hydrodynamic event. The concept proposed some years ago employed a single induction accelerator driven by a solid-state modulator system that could provide a number of variable width pulses during a single experiment. Each output pulse of the accelerator could be chopped by a fast kicker system into a beam distribution system so that different sections of the beam could hit the target from different directions. The result was a system that could provide multiple lines of sight repeatedly during a single hydrodynamic experiment.

The solid-state modulator concept is shown in figure 2. It consists of a capacitor bank charged to the working voltage and a suitable switch that is used to connect and disconnect the capacitor from the load. The load in this case is an induction core that permits the voltages of many such circuits to be summed in series to power an induction accelerator cell.

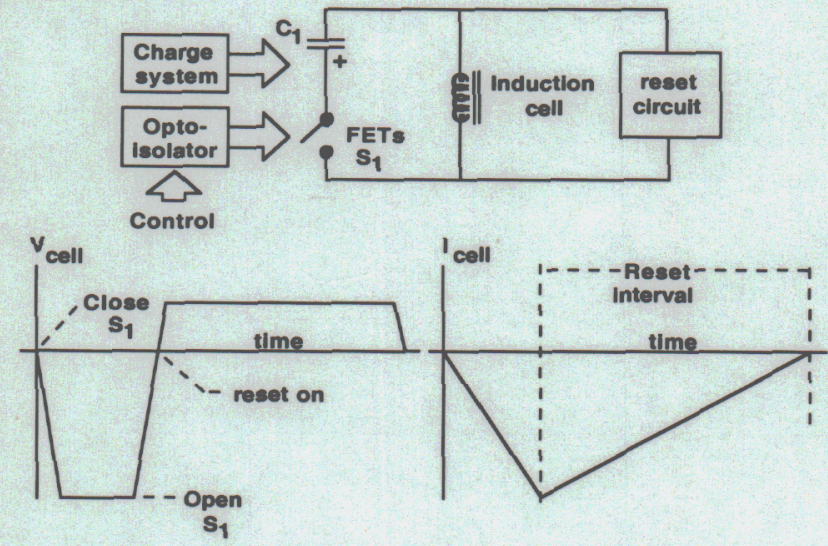

Figure 2. Modulator concept for driving an inductive voltage adder to power an accelerator cell. A pre-charged capacitor bank is connected across an induction core by a suitable switch (FET). A similar circuit with reverse polarity is provided to reset the magnetic core to prepare the system for the next pulse.

The switch in this case is a series/parallel arrangement of field effect transistors (FETs) in order to handle appreciable voltages and currents. The embodiment of this idea is the ARM-2 modulator [2]. This modulator, shown in figure 3 , has 12 FETs per circuit board with 4 such boards per layer for a current capacity of $4.8 \mathrm{kA} .22$ layers are arranged in series around a Metglas core to provide a $15 \mathrm{kV}$ modulator capable of delivering pulses $200 \mathrm{~ns}-2 \mu \mathrm{s}$ wide at up to $2 \mathrm{MHz}$ repetition rate with active core reset.

Three of these modulators are stacked in series to provide up to $45 \mathrm{kV}$ at $4.8 \mathrm{kA}$. The completed modulator is shown in figure 3 and an example designer pulse train is shown in figure 4. This modulator has produced over 1 million pulses with no discernible change in the shape or amplitude of the output waveform. This basic concept has 
given rise to several spin-off applications that will be covered in succeeding sections.

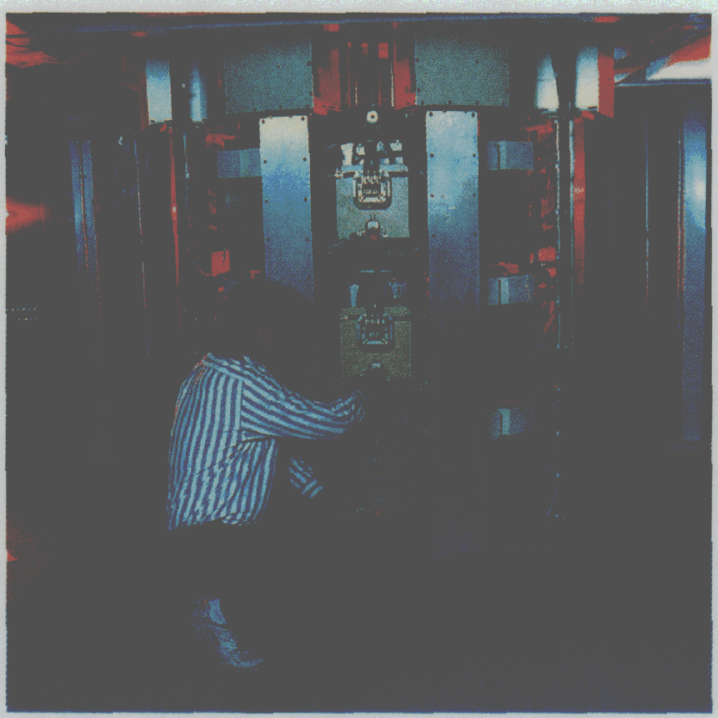

Figure 3. The completed ARM modulator. It delivers 45 $\mathrm{kV}$ at $4.8 \mathrm{kA}$ with variable width pulses at up to $2 \mathrm{MHz}$ repetition rate.

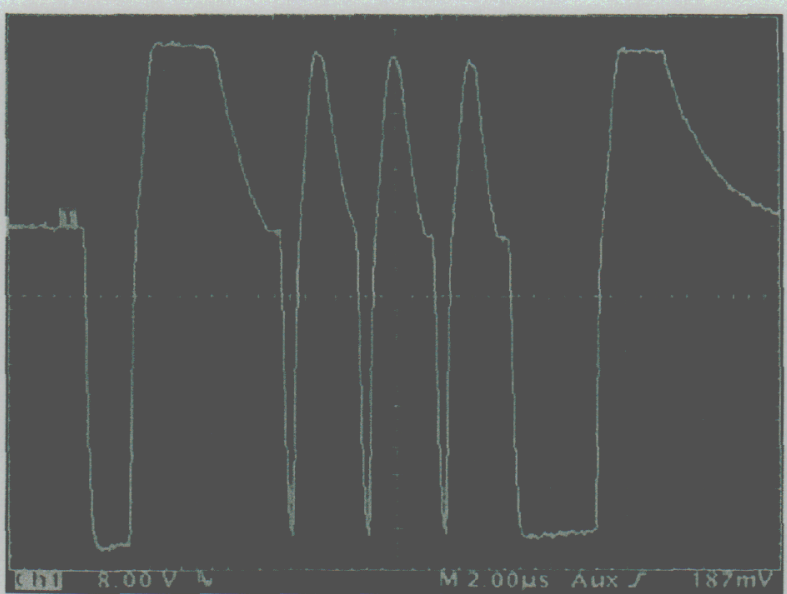

Figure 4. An example waveform showing the flexibility of the system. The output pulses are negative and the reset voltages are positive. First is a $1 \mu \mathrm{s}$ pulse followed by $3,200 \mathrm{~ns}$ pulses (all with reset) followed by a $2 \mu$ s pulse.

\section{FAST, HIGH CURRENT KICKER SYSTEM}

A fast kicker system can be realized by employing the basic geometry of a stripline beam position monitor [1]. The system consists of an outer cylindrical vacuum housing which encloses four equal size striplines. All of the upstream ends of the striplines are terminated via feedthrus in their matched impedance of $50 \Omega$. The downstream ends of the strips can be connected to pulsers via transit time isolated cables. To steer the beam in one plane only an opposite pair of strips need be driven with opposite polarities while the remaining two are terminated. By driving all four striplines the beam may be steered arbitrarily in the transverse plane. Because the pulsers used are unipolar, a DC bias dipole pair is wound over the vacuum housing to permit operation over the entire desired range.

By simply reversing the polarity of one of the two driven plates the kicker can be converted into a fast quadrupole lens. A schematic of the basic system is shown in figure 5. A kicker used on the $6 \mathrm{MeV}, 2 \mathrm{kA}$ ETA-II accelerator is shown in figure 6.

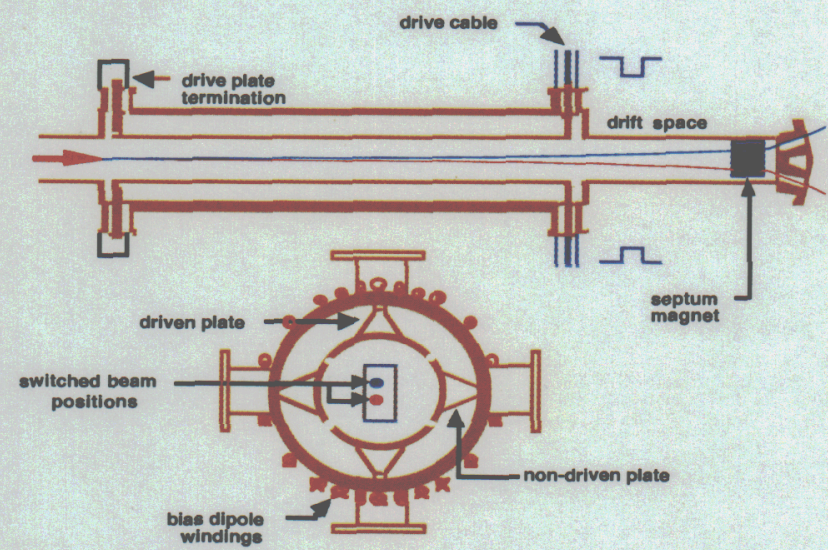

Figure 5. Fast kicker has the basic geometry of a stripline beam position monitor with four electrodes inside a vacuum housing. By powering two of the four plates the beam may be steered in one plane.

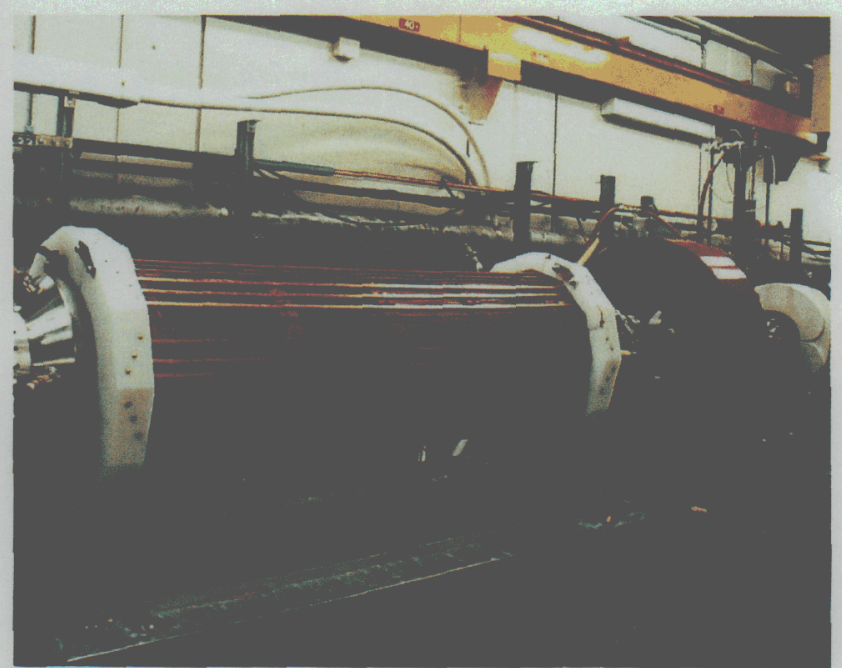

Figure 6. ETA-II kicker designed to operate at $6 \mathrm{MeV}$ with a $2 \mathrm{kA}$ beam current. The DC bias dipoles can be seen wrapped around the outside of the vacuum housing. The large red torus on the right is a solenoid that is used to match the beam into the kicker (the beam propagates from right to left). The kicker is about 1.6 meters in length and the striplines have a radius of $12.7 \mathrm{~cm}$.

The kicker is able to generate significant centroid displacements downstream of a short drift space. Images capturing the switching of a single ETA-II $50 \mathrm{~ns}$ beam pulse can be seen in figure 7 for the dipole configuration. When the pulser polarity on one of the strips is reversed to make a quadrupole the resulting elliptical beam profile can be seen in figure 8 . 


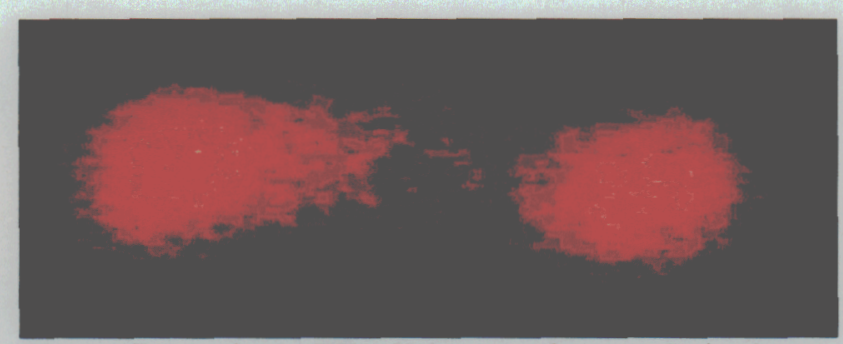

Figure 7. A single ETA-II beam pulse caught in the act of switching positions. The image is recorded light generated when the beam strikes a quartz foil $40 \mathrm{~cm}$ downstream of the kicker. The shift of the beam centroid is $4 \mathrm{~cm}$ with an applied pulser voltage of $\pm 9 \mathrm{kV}$.

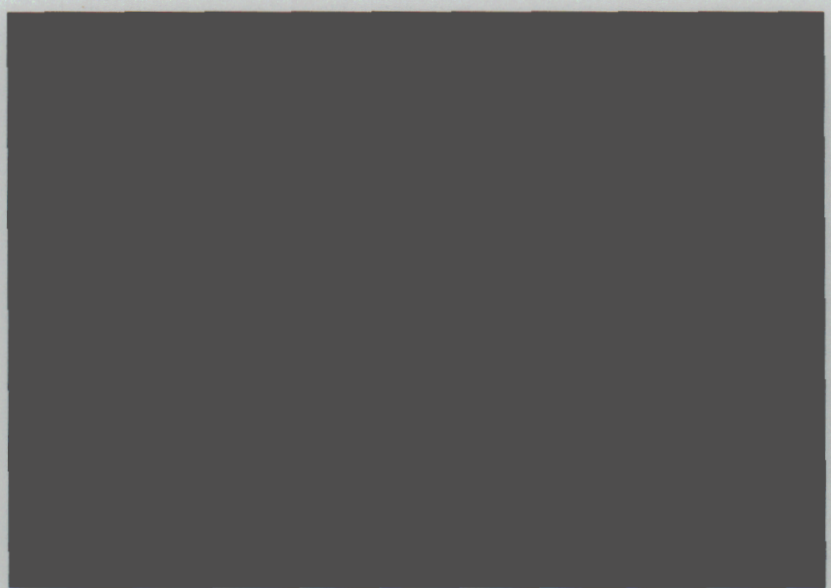

Figure 8. Reversing the polarity of one of the striplines produces a time dependent quadrupole field in the kicker that generates an elliptical beam downstream.

\section{DARHT-2 IMPLEMENTATION OF ADVANCED TECHNOLOGY}

DARHT-2 is an advanced radiographic source under construction at the Los Alamos National Laboratory. This induction accelerator will produce an $18 \mathrm{MeV}, 2 \mathrm{kA}$ beam that is $2 \mu$ s long. A fast kicker system of the type described above will be used to alternately deflect the beam into a dump or straight ahead to the $\mathrm{x}$-ray targets in order to produce four short $\mathrm{x}$-ray pulses (of order tens of ns in length) evenly spread over $2 \mu \mathrm{s}$. This concept is illustrated in figure 9.

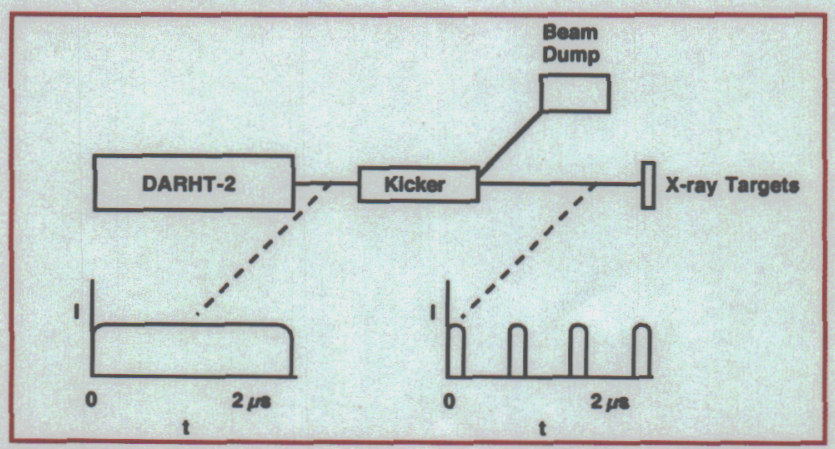

Figure 9. A fast kicker is used to produce 4 radiographic pulses in DARHT-2.
In the original kicker experiments at LLNL the pulsers employed were hard tube modulators using planar triodes. Because these tubes became difficult to obtain and because pulser voltages up to about $20 \mathrm{kV}$ were desired solid-state pulsers were developed to drive the DARHT kicker. The architecture employed is very similar to that shown in figure 2 except that each layer has its own induction core [3]. Some of the layers are charged to different voltages and can be switched on and off independently of the others. This permits the waveform of the pulsers to be adjusted rapidly in shape. This feature is employed in a pulse to pulse control system that regulates the output beam position to about $\pm 1 \mathrm{~mm}$. The completed system of two pulsers and control rack is shown in figure 10 . A plot showing the regulated switched beam position is shown in figure 11 [4].

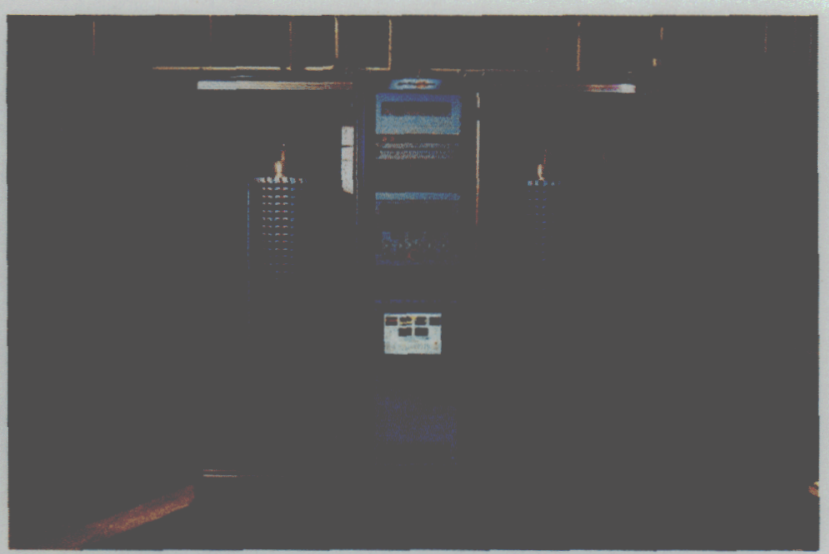

Figure 10. The completed DARHT-2 kicker pulser system. The pulsers deliver up to $18 \mathrm{kV}$ and have a $20 \%$ modulation capability.

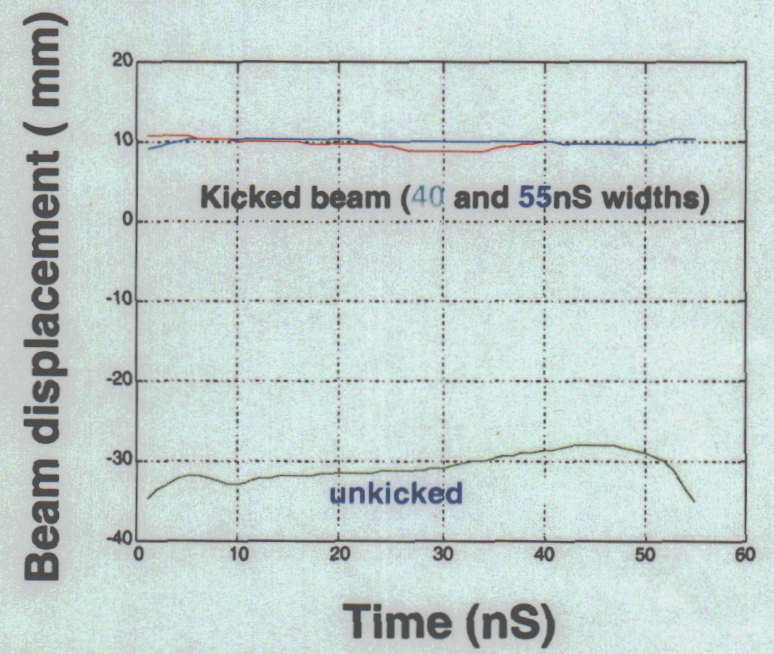

Figure 11. Output centroid position of beam downstream of the kicker system using the control system. The position of the beam without pulser input (unkicked) and with controlled pulser input for two different beam pulsewidths is shown. The switched beam position is regulated to within $\pm 1 \mathrm{~mm}$.

\section{PROTON AHF KICKER}

The same pulser technology developed for the DARHT2 kicker is being applied to drive the kickers for the proton 
radiography Advanced Hydrotest Facility (AHF) [5]. This system requires a $50 \mathrm{kV}$ drive pulse into $50 \Omega$ with a $5 \mathrm{MHz}$ burst rate capability. A prototype driver is shown in figure 12. A burst of pulses is shown in figure 13.

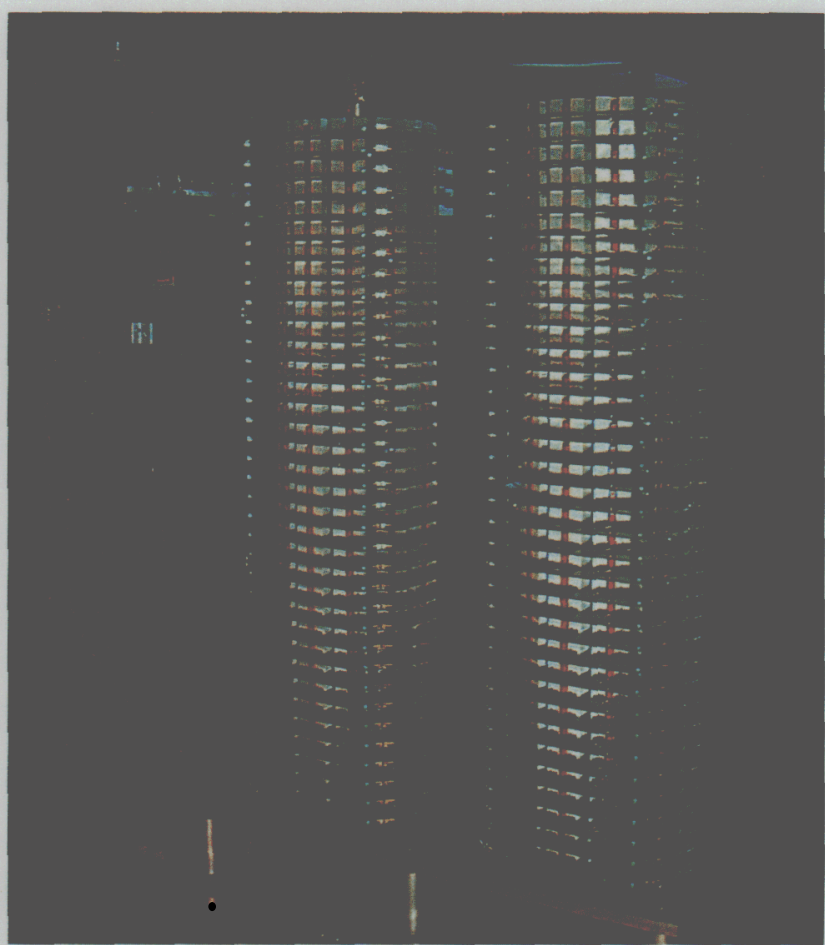

Figure 12. The prototype $50 \mathrm{kV}$ modulator. The columns shown here are in series. The modulator has been moved to a new laboratory where the two columns have been assembled in-line to improve the voltage waveforms.

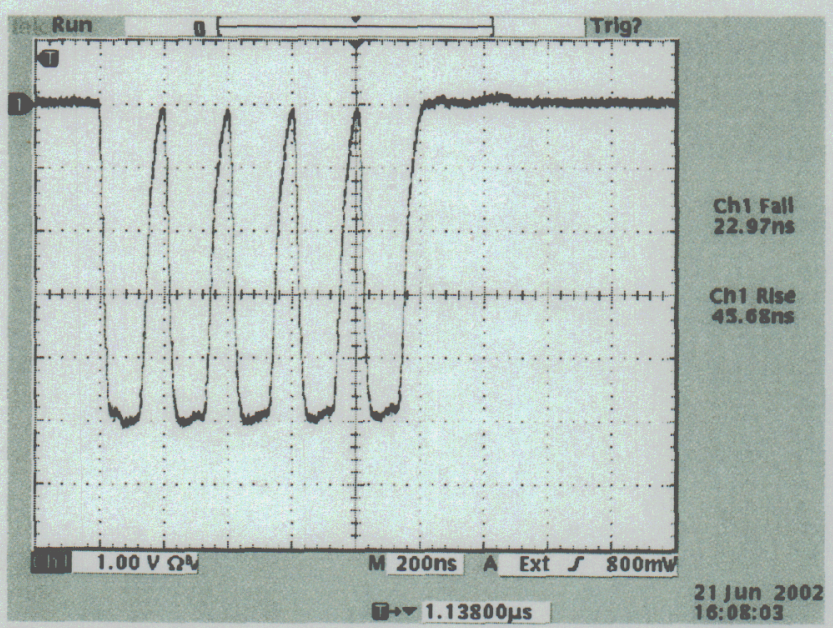

Figure 13. A five pulse burst at $5 \mathrm{MHz}$ without reset. The vertical scale is $10 \mathrm{kV} /$ division.

\section{SOLID-STATE KLYSTRON DRIVERS FOR THE NLC}

The architecture of figure 2 is being applied to drive klystrons for the Next Linear Collider (NLC) project at SLAC. In this case IGBTs are used rather than FETs to reduce the parts count and cost. The system concept is shown in figure 14 . The modulator will produce $500 \mathrm{kV}$ at $2 \mathrm{kA}$ to drive 8 klystrons at an average power of 500 $\mathrm{kW}$ [6]. A single layer of the modulator is shown in figure 15 . The IGBT which powers these boards is shown in figure 16.

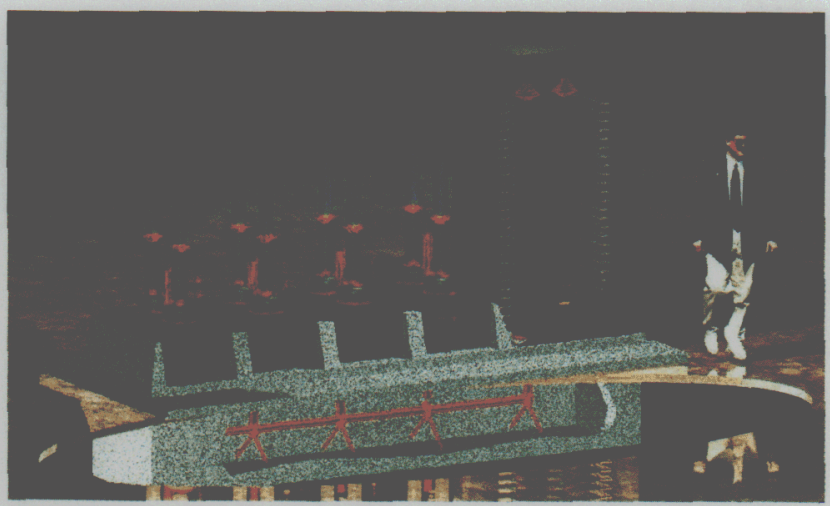

Figure 14. Solid-state driver for 8 NLC klystrons. Each klystron is $75 \mathrm{MW}$ peak power.

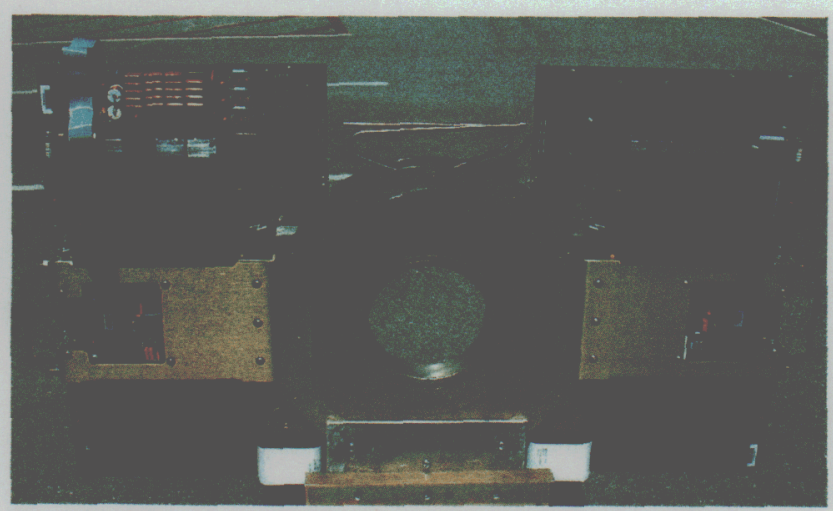

Figure 15. A single layer of the modulator showing two switch boards. The IGBTs are hidden under the two metal plates emanating horizontally from the Metglas core in the center.

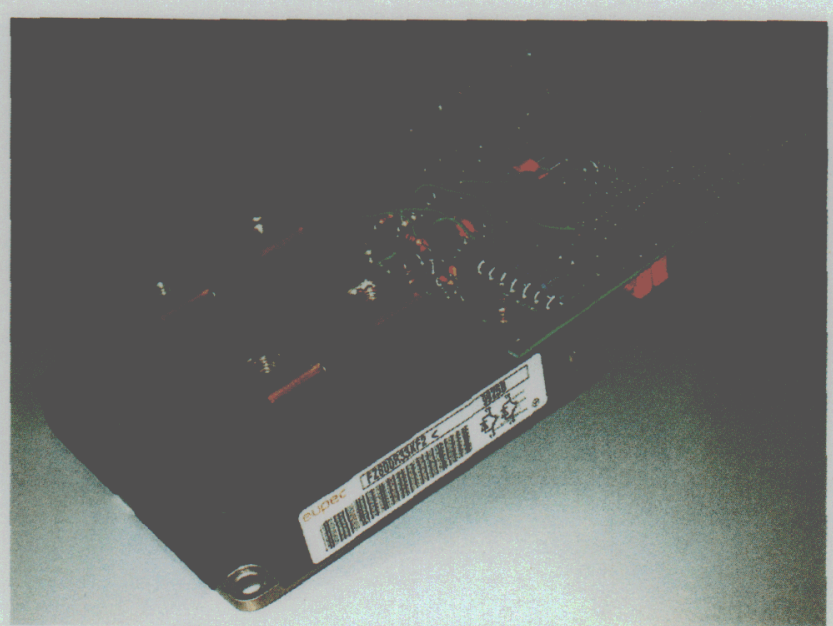

Figure 16. EUPEC $3.3 \mathrm{kV}, 800$ Amp IGBT.

The completed prototype modulator driving several klystrons can be seen in figure 17. 


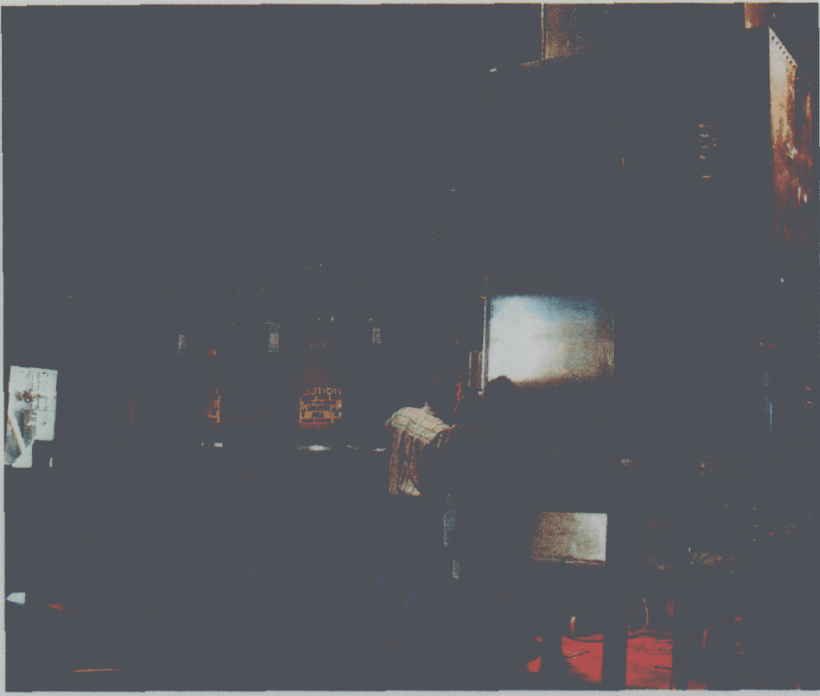

Figure 17. Assembled prototype modulator driving "dog" (out of specification) klystrons.

\section{HIGH GRADIENT INSULATORS}

Insulators with superior breakdown characteristics have been developed for a compact accelerator concept [7]. These configurations are characterized by the presence of many intervening, floating electrodes between layers of conventional dielectric materials such as lexan, rexolite, fused silica, etc. The period of the intermediate electrode spacing ranges from several $\mathrm{mm}$ down to tenths of a $\mathrm{mm}$. An insulator that was exposed directly to an intense electron beam is shown in figure 18. This insulator was placed directly across the accelerating gap of an induction cell placed at the downstream end of the ETA-II accelerator.

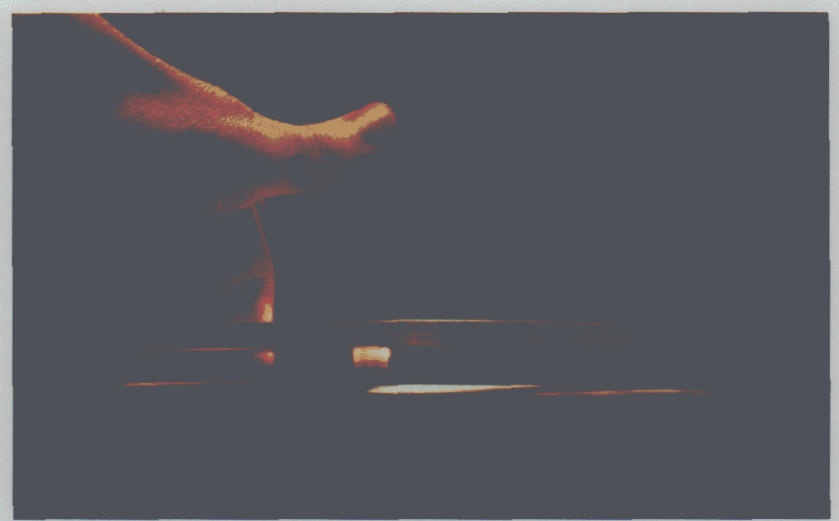

Figure 18. A high gradient insulator composed of thin layers of rexolite interspersed with stainless steel electrodes. The height of the assembly is $1 \mathrm{~cm}$.

A $2 \mathrm{kA}, 50 \mathrm{~ns}, 6 \mathrm{MeV}$ electron beam pulse was passed through the cell at a repetition rate of $1 \mathrm{~Hz}$ for the better part of a day. The beam return current was forced through load resistors to generate a voltage across the cell. The results are shown in figure 19 . No breakdowns were observed even up to a stress of $180 \mathrm{kV} / \mathrm{cm}$. The lower voltage trace is characteristic of the normal operation of an ETA-II cell with a monolithic, angled rexolite insulator (3.75 cm length).

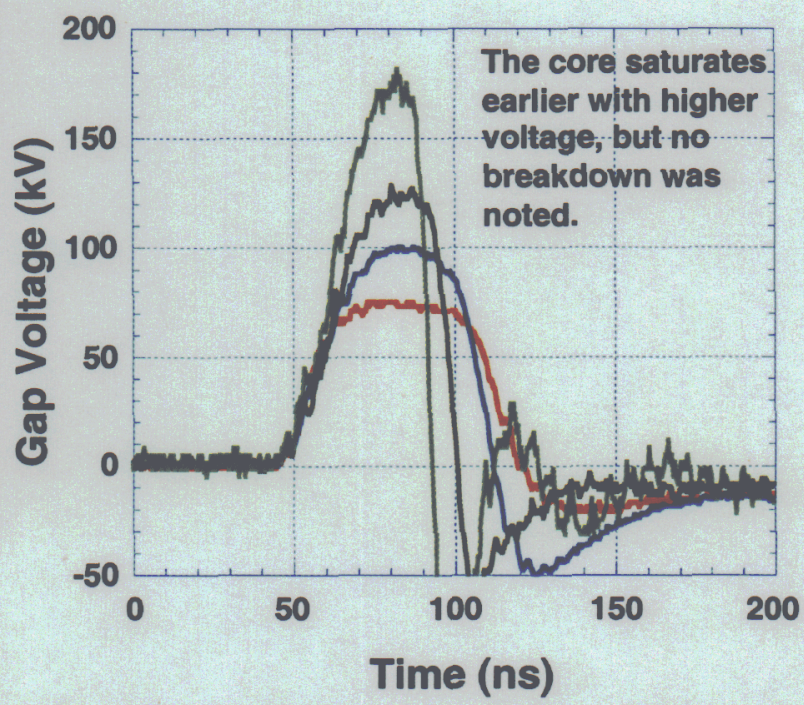

Figure 19. The cell voltage waveforms for different load resistors

\section{CONCLUSIONS}

We have described advanced technology that was inspired by a concept for advanced radiography. This lead directly to solid-state modulators of unprecedented flexibility, speed and power capability that can be used to drive induction accelerators, klystrons for RF machines and fast dipole and quadrupole lenses opening up new opportunities for accelerator design and beam control. In addition, new insulator technology has been described that will be useful in conventional and novel high gradient accelerators.

\section{REFERENCES}

[1] G.J. Caporaso, "Linear Induction Accelerator Approach for Advanced Radiography," 1997 Particle Accelerator Conference

[2] H.C. Kirbie, et al. "Development of Solid-State Induction Modulators for High PRF Accelerators," Lawrence Livermore National Laboratory, Livermore, CA, UCRL-JC-119582, Proceedings of the $10^{\text {th }}$ IEEE Pulsed Power Conference, Albuquerque, NM, July 10-13, 1995.

[3] E.G. Cook et al, "Solid-State Kicker Pulser for DARHT-2," $13^{\text {th }}$ IEEE International Pulsed Power and Plasma Science Conference, Las Vegas, NV, June 17-22, 2001

[4] J.A. Watson, et al, "A Solid-State Modulator for High Speed Kickers," 2001 Particle Accelerator Conference

[5] E.G. Cook et al., "Design and Testing of a Fast, $50 \mathrm{kV}$ SolidState Kicker Pulser," 2002 Int. Power Modulator Conf. and High Voltage Workshop

[6] R.L. Cassel et al.,"The Prototype Solid State Induction Modulator for SLAC NLC," 2001 Particle Accelerator Conference

[7] S. Sampayan et al.,"High-Performance Insulator Structures for Accelerator Applications," 1997 Particle Accelerator Conference 